\title{
Towards Data Exchange between Health Information System and Insurance Claims Management System
}

\author{
Abel Haule \\ Nelson Mandela African Institution of Science and Technology, P. O. Box 447, Arusha, Tanzania \\ Mwenge Catholic University, P. O. Box 1226, Moshi, Tanzania \\ Email: haulea@nm-aist.ac.tz or kimuchu2004@gmail.com \\ Mussa Ally Dida and Anael Elikana Sam \\ The Nelson Mandela Institution of Science and Technology, PO Box 447 Arusha, Tanzania \\ Email: \{mussa.ally, anael.sam\}@nm-aist.ac.tz
}

Received: 14 September 2018; Accepted: 14 December 2018; Published: 08 March 2019

\begin{abstract}
The advancement of technology observed today has led to the development of many Health Information Systems (HIS) which are cost-effective, reliable, scalable and flexible. Moreover, integrated Health Information System (iHIS) plays a crucial role in the dissemination of information, which helps in decision-making. The care $2 x$ HIS in Tanzania does not have a module for exchanging data between Care 2x HIS and the National Health Insurance Fund (NHIF) claims management system. The absence of this module in Care2x has resulted into long waiting time for a patient, inaccuracy of the data submitted in claim forms, the consumption of time when processing claims, delay in processing payment and the high costs incurred in printing claims forms. In this paper, we used both qualitative and quantitative methods to gather the requirements for the development of the module. Interviews, questionnaire and document review were employed in data collection. The requirements were gathered with the help of 12 practitioners and one Information Technology (IT) specialist from NHIF headquarters. The results showed that the integration of the data exchange module is very potential in solving the present challenges. The data exchange module between Care2x HIS and NHIF Claims management System will increase the accuracy of claims submitted and reduce the cost for printing claims forms and time spent in filling and processing claims.
\end{abstract}

Index Terms-Hospital Information System, Data Exchange, System Integration, Care2x.

\section{INTRODUCTION}

The rapid development of Information and Communication Technology (ICT) has led to the usage of Health Information Systems (HIS) in health care facilities to manage, store, protect and share medical information
[1]. The use of hospital management systems is recognized by the Tanzania government through Tanzania National E-health Strategy 2013-2018. The strategy was aimed at integrating ICT in health so as to transform healthcare delivery by enabling information access and supporting healthcare operations, management, and decision making [2]. To implement this strategy, the Ministry of Health, Community Development, Gender, the Elderly and Children came up with the Guidelines and Standards for Integrated Health Facility Electronic Management Systems of 2016 aiming at improving quality of healthcare operations while enhancing revenue collection, management of medicines and other medical supplies in both public and private health facilities [3].

The efforts shown by Tanzania government in using ICT tools drive many health facilities to start using electronic health management information systems. The most popular HIS used in Tanzania include GoT-HoMIS, Care2x, AfyaPro, OpenMR, PatientOS, and OpenEHR. Care $2 \mathrm{x}$ is an open source hospital information system which can be customized according to the requirements of the health facility. It was implemented in more than 15 private health facilities. Tanzanian government through the President's Office - Regional Administration and Local Government (PO-RALG) also manages The Tanzania Hospital Management Information System (GoT-HoMIS), which has been implemented in more than 170 health facilities owned by the government [4].

For the improvement of health services in Tanzania cost-sharing schemes were introduced in parallel with the introduction of medical insurance schemes as a tool to overcome the challenge of unaffordable medical expenses [5]. In 1993 the government of Tanzania formulated health insurance policy, which fostered to the establishment of National Health Insurance Fund in 2001 with the objective of ensuring healthcare services to both public and private sector employees [6]. NHIF coverage is growing at a high rate and as of 30th June, 2015 it stood at 3,237,434 beneficiaries [7]. The increase in the 
number of NHIF beneficiaries pushed to the NHIF administrative to develop claims management system to assist on the management of members and claims verification.

Despite the adoption of HIS in several hospitals, and the NHIF having their own claim management information system, the NHIF patients are still handled manually and their records stored in hard copies. The NHIF print hard copy forms and submit them to the health facilities throughout the country to be filled manually by health practitioners as they attend the patients. While these information systems can be integrated and simplify the process, it is not yet so. This paper therefore reports on an on-going study that aims to integrate Care $2 x$ HIS with the NHIF claim system so as both systems can exchange required data and reduce the workload to the practitioners. The aim of this study is to analyse the requirements for development of module for data exchange between Care2x hospital system and the NHIF claim management system that will computerize NHIF patient claim form with intention to reduce patient waiting time, time spent by doctors to attend NHIF insured patients and automate the process of submitting NHIF treatment form to NHIF for verification.

\section{RELATED WORKS}

The advancement of technology has led to the development of many health information systems which are cost-effective, reliable, scalable and flexible. The main goal of HIS is to improve information flow within health institutions without altering task to health-care practitioners [8].

The study conducted by Panaviwet et al. [9] showed that long waiting time is often a problem encountered by most of the patients and it is the major cause of their dissatisfaction with the hospital services. They designed an appointment system for the outpatient department to solve a problem of patients long waiting time caused by lack of effective appointment. Simulation model used to evaluate the appointment system showed that average waiting time could be reduced by 37 to 44 percent as compared to the previous status.

In Albania, Care $2 x$ is considered as a national open source health information system where it is used to manage 100,000 patients per year in the Mother Teresa Hospital [10]. It helps in the management of health centre's workflow. It is mainly used to store, report and manage patient information within the hospital. Despite being the national health information system, it lacks a module for data exchange between care $2 \mathrm{x}$ and other health information systems.

In addition, Kanagwa et al. [11] customized Care2x and deployed in more than 200 health facilities in Uganda. Helecare $2 \mathrm{x}$ was the module customized in care $2 \mathrm{x}$ in order to assist in improving healthcare services. It was distributed in health facilities in Uganda to improve management of patient information including; patient bio-data, insurance record as well as critical medical information. Development of Helecare2x module assisted in the auto-generation of reports and submission to the relevant authorities. The study concluded that Care $2 \mathrm{x}$ is a mature product and helped to reduce the use of paper and improve workflow in health facilities. The weakness of this customized Care $2 \mathrm{x}$ was that, it was limited to outpatient only.

In AIC Kijabe hospital in Kenya there were some few challenges in providing healthcare services. The challenges included; servers were unable to cope with the load put on them and MsAccess database that was used in registering patient was slowing down. Also, there were in need of open source HIS to combine the MsAccess databases to support billing in laboratory, pharmacy, store and supplies. Due to these challenges, the hospital found an open source that assisted in solving all of the issues. They decided to use care $2 \mathrm{x}$ since it is an open source and it is manageable. Thereafter the healthcare services were improved and all the registration challenges were covered by the use of care $2 x$. However, the study did not consider the integration of care $2 \mathrm{x}$ with other health information systems [12].

The study conducted by Khan et al. [13] showed that Care 2x was customized and deployed successfully in two premiere client hospitals in India. Care2x was customized according to the requirements of information workflow in the Indian hospitals. It reduces data redundancy, which was a major problem in several health facilities in India. In addition, it was customized purposely for managing patient information and information sharing. The study described the architecture of care $2 \mathrm{x}$ which is based on the Model View Controller (MVC) that makes it easier for customization to accommodate low cost HMIS solution. However, the study did not consider the exchange of information between care $2 \mathrm{x}$ and other HMIS.

Betuel et al. [14] conducted an experiment to analyse the performance of a virtual private network on information exchange between health information systems. It fits well in exchange of information among health facilities. In Tanzania, the exchange of patient information between facilities which are using care $2 \mathrm{x}$ was done manually because care $2 \mathrm{x}$ does not have such functionality. The study focused on analysing the performance of a virtual private network instead of developing the module to assist the exchange of patient information among care $2 x$ users. On the other hand, the study was based on data exchange between homogeneous systems only (Care $2 \mathrm{x}$ to Care $2 \mathrm{x}$ ) rather than Care $2 \mathrm{x}$ and other systems.

The study done by Wambura et al. [15] described the development of a discharge letter module to assist in communicating information of patients hospital visit, treatment and care plans to the next caregiver and hospital. A discharge letter module for Care2x was developed specifically for exchanging information with the patient and other healthcare providers. The discharge letter module in care $2 \mathrm{x}$ helps to reduce handwriting human errors and enhance good communication between inpatient and outpatient caregivers in following the progress of the patient. However, the information exchange is done by printing information from the system 
and submitted in paper-based to the intended user. This module does not support electronic data exchange between hospitals and other health-care providers. Therefore, the study proposes the development of data exchange module between Care $2 x$ and NHIF claim management system which will automate claims submission, reduce cost and time in processing claims thus increases the level of customer satisfaction and improve hospital workflow. On the other hand, NHIF will be able to receive and verify claims in time which will easy payment processes.

\section{MATERIAL AND MethodS}

The study was conducted at Arusha and Kilimanjaro regions in Tanzania. These two regions are located in the northern zone of Tanzania with 1260 health facilities in total [16]. In this zone, there were more than 9 health facilities which were using Care2x. The target groups were healthcare institutions which are using the Care $2 \mathrm{x}$ system, the Care $2 \mathrm{x}$ technical service providers and the NHIF office. The motive for selecting northern zone for this study is because it has a large number of health facilities compared to other zones. Moreover, Arusha and Kilimanjaro regions were selected due to the fact that they have a large number of hospitals which are using HIS such as Care2x. Hospitals involved in this study were Arusha Lutheran Medical Centre (ALMC) from Arusha region and Kibong'oto National Tuberculosis Hospital (KNTH) located in the Siha district of Kilimanjaro region.

\section{A. Sample Size and Sampling Technique}

The study involved a total of 15 respondents from different areas, 12 of the respondents were physicians from the two health facilities, two were technical persons from Lutheran Investment Company (LUICO) and one IT specialist from NHIF headquarters. Random purposeful sampling technique was used in selecting representative hospitals based on the experience in using Care2x. Furthermore, this technique was also employed to get eight (8) representative doctors and two nurses from each hospital.

\section{B. Data Collection Methods}

Data were collected from the study area in the period of January to April 2018. The study employed document review, interview and questionnaire as tools for data collection.

Questionnaire: Questionnaires were distributed to doctors and nurses to gather information about their experience in filling claim forms and using Care $2 x$. Open-ended questions, close-ended questions, multiple choices questions and scale questions were used.

Interview: Structured interview with interview guide questions were conducted to technical team from LUICO to gather information about their experience in customizing and managing Care $2 x$. Furthermore, we interviewed IT specialist from NHIF who is managing claim management system in order to understand claims submission flow and the challenges.

Document review: During the study we reviewed different documents including Care $2 \mathrm{x}$ documentation, Care $2 \mathrm{x}$ database structure, "standards and guidelines for electronic data exchange between NHIF and service providers" and "Integration API for Electronic Data Exchange with Health Service Providers".

\section{RESULTS}

\section{A. Overview of the Existing System}

The interviews conducted at ALMC and KNTH hospitals were meant to understand the existing claim processing system and how it works. The study revealed that there are some difficulties in filling claim forms such as searching drug and services codes in the printed book, which consume a lot of time. Also, respondents claimed that claim forms were filled twice, in the hard copy and also filled into the NHIF claim system.

Moreover, the study found that NHIF spent a lot of money in printing claim forms. Also, the healthcare provider loses a lot of money due to claims which were rejected. Since claim forms are filled in hard copy, some forms were incomplete/wrongly filled which led to the rejection of the claim by NHIF. For example, at Kibong'oto National Tuberculosis Hospital in 2016 out of 3499 claims submitted, 207 of them were incomplete and hence rejected.

Due to the challenges revealed by respondents, most $(87 \%)$ of them agreed into the development of data exchange module between Care $2 x$ and NHIF claim management system to increase accuracy in filling forms, reduce patient waiting time and time spent in filing claim forms.

Table 1. Responses for the integrated Care2x system and NHIF claims management system will reduce paper

\begin{tabular}{|l|c|c|c|}
\hline & Frequency & Percent & Cumulative percent \\
\hline Strongly Agree & 10 & 67 & 67 \\
\hline Agree & 3 & 20 & 87 \\
\hline Neutral & 2 & 13 & 100 \\
\hline Disagree & 0 & 0 & 100 \\
\hline Strongly Disagree & 0 & 0 & 100 \\
\hline
\end{tabular}

B. Technology Description

This paper presents both functional and non-function requirements for the development of a data exchange module. Functional requirements express what the data exchange module will provide to Care $2 \mathrm{x}$ users while nonfunction requirements describe the properties of the system.

\section{Functional Requirements}

(a) The module must be able to extract mandatory information from car $2 x$ required for claim.

(b) Generated list of claims must contain only discharge patients folio(s)

(c) Mandatory claim information must be validated before submission 
(d) User must be able to view pending claims

(e) User must be able to view claim detail for each folio

(f) Claims must be confirmed before submission

(g) Only confirmed claims must be submitted (h) User must be able to generate report of submitted claims

(i) User must be able to export report of submitted claim

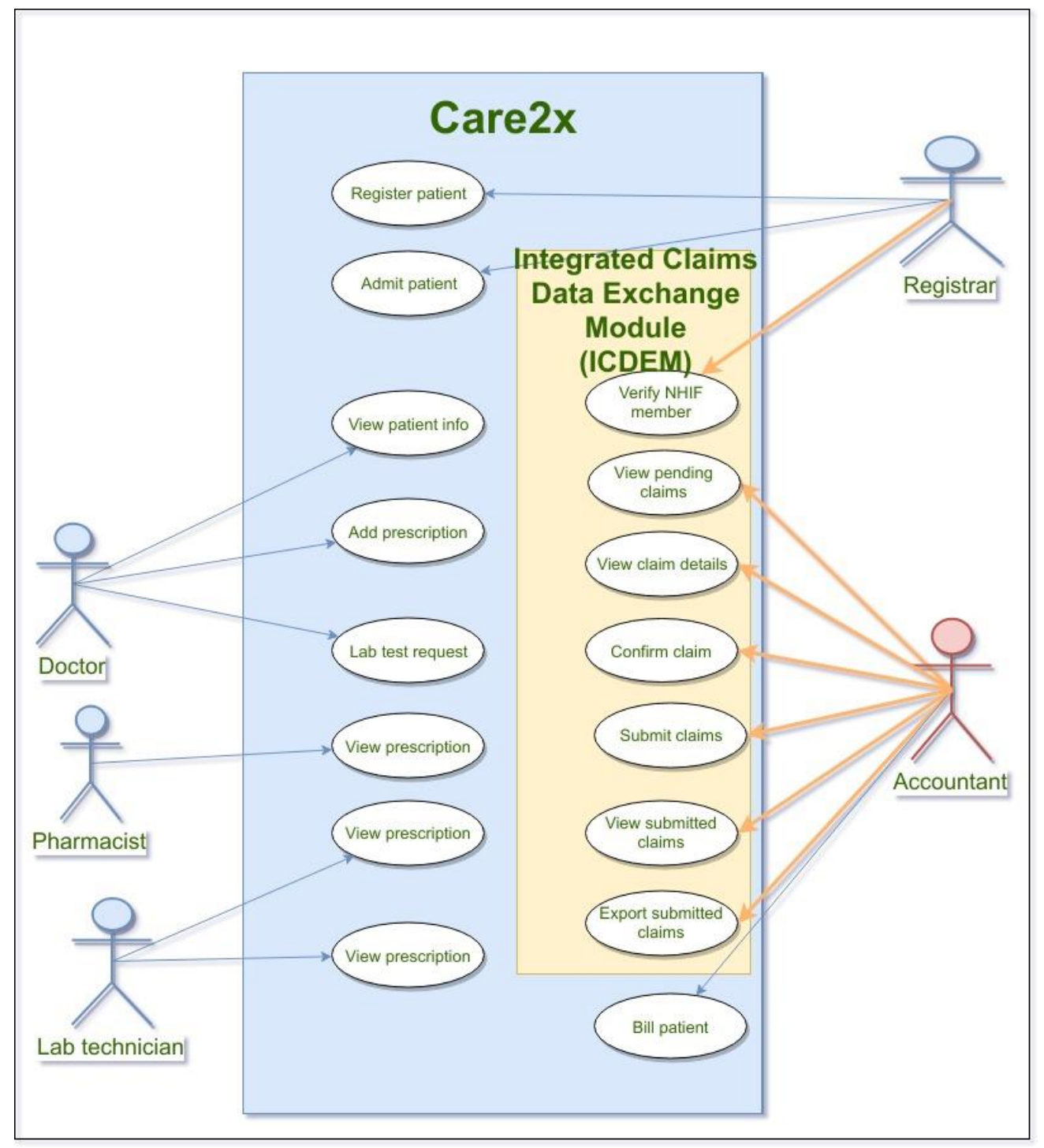

Fig.1. Use case diagram for data exchange module

\section{Non-function Requirements}

System Interoperability. After review of Care $2 \mathrm{x}$ documentation, database structure and the system codes, Standards and Guidelines for Electronic Data Exchange between NHIF and Service Providers and Integration API for Electronic Data Exchange with Health Service Providers documents we have discovered that the two systems share information in very low level which has the impact in patient care. Furthermore, we noted the following information is missing in Care $2 x$ but are required by NHIF during claim submission.

1) Practitioner number (License number given by Medical Council of Tanganyika), which will be used to identify health practitioner who treated the patient.
2) NHIF codes for Drugs, Investigation, Surgery and Services. Which are used as reference of service during processing claim.

3) Folio Id, which is unique number which identifies batch of claims submitted to NHIF

4) Folio Item ID - a is unique value which identifies specific item claimed

5) Folio-No - is similar to serial numbers of folios.

6) Visit type - type of visit of a patient like normal visit or emergency visit

7) Referral number - a reference number given to patient transferred from one hospital to another.

8) Different version of International Classification of Diseases (ICD) where NHIF system use ICD-9 while Care2x uses ICD-10. Mapping will be done between ICD-9 and ICD-10. 
Table 2. Description of functional requirements for data exchange module

\begin{tabular}{|c|c|}
\hline $\begin{array}{l}\text { REQUIREMENT } \\
\mathbf{S}\end{array}$ & DESCRIPTION \\
\hline $\begin{array}{l}\text { Verify } \\
\text { Member }\end{array}$ & $\begin{array}{l}\text { The Module will verify the validity of NHIF } \\
\text { member by using membership number }\end{array}$ \\
\hline $\begin{array}{l}\text { View } \\
\text { Claims }\end{array}$ & $\begin{array}{l}\text { The Module will generate the list of pending } \\
\text { claims of a given range of date. The system will } \\
\text { compute the amount which is claimed for each } \\
\text { folio. }\end{array}$ \\
\hline View Claim details & $\begin{array}{l}\text { The claim processing personnel will be able to } \\
\text { view the details of the claim. This view will be } \\
\text { similar to the paper-based claim form. }\end{array}$ \\
\hline Confirm Claim & $\begin{array}{l}\text { The claim processing personnel will confirm the } \\
\text { claim ready for submission. The system will } \\
\text { validate if all required information is available for } \\
\text { claim submission. }\end{array}$ \\
\hline Submit Claim & $\begin{array}{l}\text { The only confirmed claim will be submitted to } \\
\text { NHIF. }\end{array}$ \\
\hline $\begin{array}{l}\text { Generate submitted } \\
\text { claims report }\end{array}$ & $\begin{array}{l}\text { The module will generate a report of submitted } \\
\text { claims. }\end{array}$ \\
\hline $\begin{array}{l}\text { Export submitted } \\
\text { claims }\end{array}$ & $\begin{array}{l}\text { The system will export a report of claims } \\
\text { submitted in form of Portable Document File } \\
\text { (PDF), Excel and Comma Separated Values } \\
\text { (CSV) }\end{array}$ \\
\hline
\end{tabular}

Data Exchange Structure. Integration API for Electronic Data Exchange with Health Service Providers document show data exchange structure is JavaScript Object Notation Syntax (JSON). A claim can be submitted online to NHIF by creating a Jason payload. This payload can contain one or more folios (At least one folio) and associated details.

Security for data exchange. The security will be taken into account when developing API in NHIF system in which each health facility provider will have username and password which are used to login. After successful login in NHIF system, the system generates a token which will be valid for a specific time. Token will be generated to make a connection between care $2 \mathrm{x}$ and NHIF system during data exchange. Care $2 \mathrm{x}$ was implemented using role-based access control (RBAC) in which user can perform a specific task based on the assigned role.

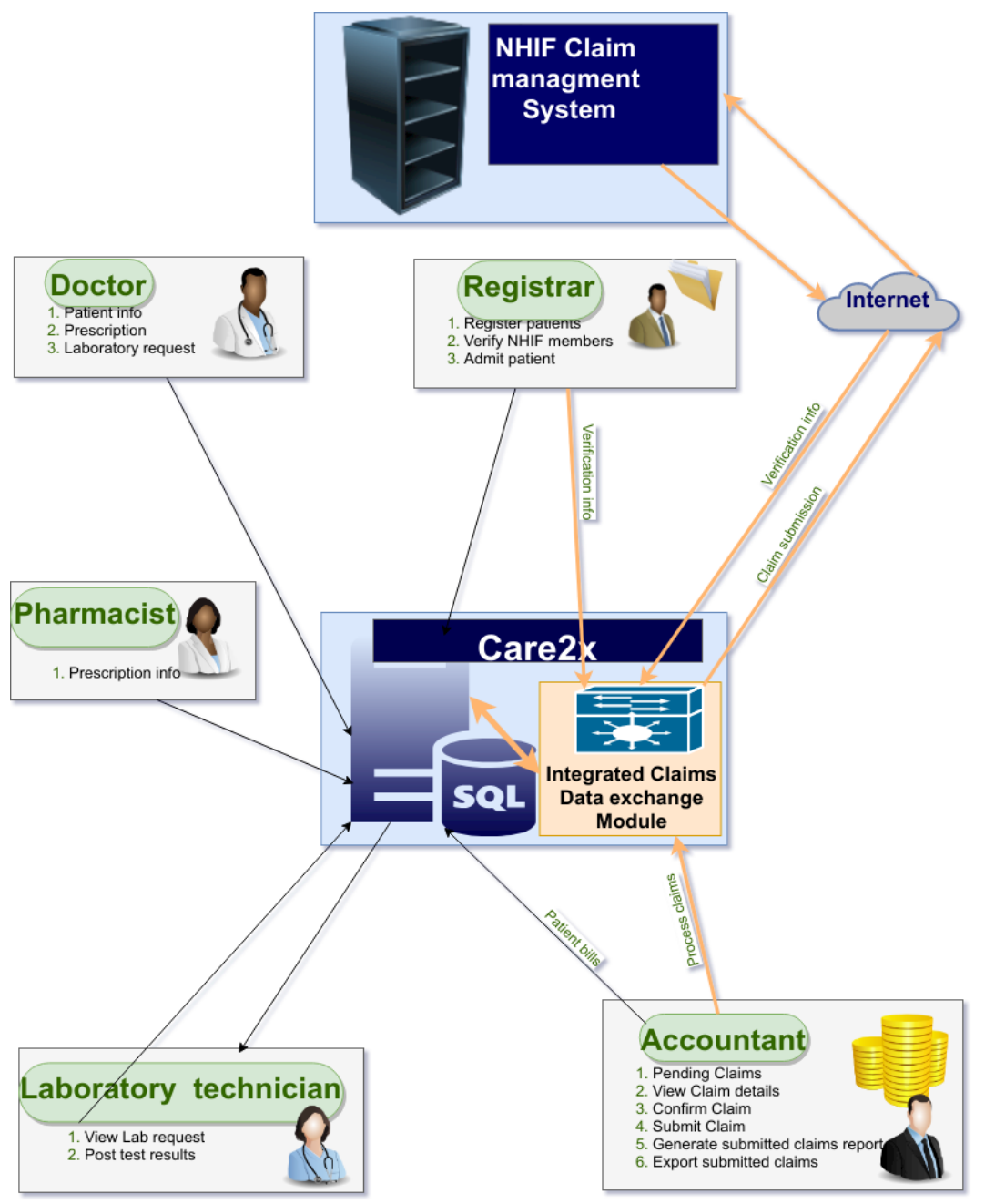

Fig.2. Conceptual framework of data exchange module. 


\section{DISCUSSION}

Based on the study findings, several challenges on claims processing were identified, such as; incomplete or wrongly filled claim forms, time spent in filling claims forms, cost incurred in printing claim forms and difficulties in search drugs and service codes. Incomplete or wrongly filled claim forms were rejected by NHIF and led to the loss of revenue to health-care providers. NHIF is responsible for printing claim forms, which are very cost-full and lead to loss of revenue.

Therefore, in solving the mentioned problems the study proposes the development of a data exchange module. The results indicate the importance of integration module which will reduce errors in filling claims forms, reduce time spent by doctors in filling claim forms which will be accessed and filled automatically from the Care $2 x$ system. The proposed solution provides integration between the two systems (Care2x and NHIF claim system) which reduce the workload of physicians from a specific hospital who were required to submit a claim form in hard-copy to NHIF office.

The proposed solution will help to generate reports of claims submitted and claims which are pending. Future work will involve the design and development of a data exchange module between Care $2 \mathrm{x}$ and NHIF claim management system. The development will involve the use of several tools, software, and programming language which includes JavaScript, HTML, PHP, JAVA, MySQL, and Net-beans.

\section{CONCLUSION}

In this paper, we have analysed the requirements for data exchange module between Care $2 x$ and NHIF claim management system. The study showed that the proposed solution is very significant to NHIF health services providers and NHIF insured patient. If accepted and deployed in the Care $2 \mathrm{x}$ HIS, the proposed system will minimize cost which used to prepare patient claim forms. Moreover, the module helps to reduce the work done in manual verifying claims forms.

Furthermore, there will be a huge reduction in a number of rejected claims due to incomplete filled forms as the module will help verify the information before submission to NHIF. By implementing the proposed module there will be an increase in revenue collection to the healthcare providers. Lastly by eliminating repeated work of filling information in claim forms and Care $2 \mathrm{x}$ system the proposed solution will reduce patient waiting time.

\section{REFERENCES}

[1] WHO. Management of patient information. Glob Obs eHealth Ser [Internet]. 2012 [cited 2018 Aug 30];6:80. Available

from: http://apps.who.int/iris/bitstream/handle/10665/76794/978 9241504645_eng.pdf? sequence $=1 \&$ isAllowed=y
[2] MoHSW. Tanzania National eHealth Strategy 2013-2018. 2012;(May):44. Available from: http://www.tzdpg.or.tz/fileadmin/documents/dpg_internal/ dpg_working_groups_clusters/cluster_2/health/Key_Secto r_Documents/Tanzania_Key_Health_Documents/Tz_eHe alth_Strategy_Final.pdf

[3] MoHCDGEC. Guidelines and Standards for Integrated Health Facility Electronic Management Systems. 2016.

[4] PORALG. Government of Tanzania - Hospital Management Information System (GoT-HoMIS). 2017 [cited 2017 Oct 30];1-19. Available from: https://www.healthdatacollaborative.org/fileadmin/upload s/hdc/Documents/Country_documents/Tanzania_GOTHOMIS_presentation_12Sept2017.pdf

[5] Kumburu PN. National Health Insurance Fund (NHIF) in Tanzania as a Tool for Improving Universal Coverage and Accessibility to Health Care Services: Case from Dar Es Salaam - Tanzania [Internet]. Mzumbe University; 2015 [cited 2017 May 10]. Available from: http://scholar.mzumbe.ac.tz/bitstream/handle/11192/1028/ Msc-MHSM-Paschal Nathan KUMBURU 2015.pdf? sequence $=1$

[6] Ministry of Health. National Health Policy [Internet]. Ministry of Health. 2003 [cited 2018 Jul 12]. Available from:

http://apps.who.int/medicinedocs/documents/s18419en/s1 8419en.pdf

[7] NHIF. NHIF-Profile [Internet]. NHIF. 2015 [cited 2017 May 2]. Available from: http://www.nhif.or.tz/index.php/about-us/profile

[8] El Azami I, Cherkaoui Malki MO, Tahon C. Integrating Hospital Information Systems in Healthcare Institutions: A Mediation Architecture. J Med Syst [Internet]. 2012 Oct 16 [cited 2017 Oct 31];36(5):3123-34. Available from: http://link.springer.com/10.1007/s10916-011-9797-8

[9] Panaviwat C, Lohasiriwat H, Tharmmaphornphilas W. Designing an appointment system for an outpatient department. IOP Conf Ser Mater Sci Eng [Internet]. 2014 Jun 23 [cited 2017 Mar 10];58(1):012010. Available from: http://stacks.iop.org/1757-

$899 X / 58 / \mathrm{i}=1 / \mathrm{a}=012010$ ?key=crossref.635378c5d2afa5cac 7baa797bdcc7e0e[10] Hillenius G. Albania Considering Care2x as a National Open Source Health Information System [Internet]. Open Health News. 2014 [cited 2017 Nov 1]. Available from: http://www.openhealthnews.com/story/2014-11-

04/albania-considering-care2x-national-open-sourcehealth-information-system

[10] Kanagwa B, Ntacyo J, Orach S. Towards paperless hospitals: Lessons learned from 15 health facilities in Uganda. Adv Intell Syst Comput. 2016;445:23-32.

[11] Drury P, Dahlman B. Open source approaches to health information systems in Kenya. World Hosp Health Serv [Internet]. 2005 [cited 2018 Aug 30];41(3):36-9. Available from: https://pdfs.semanticscholar.org/d365/4fc9b0168022134c 73ef8e639a9b5b90403c.pdf

[12] Khan MT, Shamimul, Sinha RR. Adaptation of Open Source Software for Healthcare in India: Case of CARE2X. J Eng Appl Sci [Internet]. 2017 [cited 2017 Nov 1];12(10):2603-12. Available from: https://www.medwelljournals.com/abstract/?doi=jeasci.20 17.2603.2612

[13] Betuel S, Machuve D, Kalegele K. Applied medical informatics. Appl Med Informatics [Internet]. 2017 Jul 27 [cited 2018 Jul 12];39(1-2):21-9. Available from: http://ami.info.umfcluj.ro/index.php/AMI/article/view/620 
[14] Wambura W, Machuve D, NYKÄNEN P. Journal of health informatics in developing countries. J Health Inform Dev Ctries [Internet]. 2017 Dec 10 [cited 2018 Jul 12];11(2). Available from: http://jhidc.org/index.php/jhidc/article/view/168

[15] MoHCDGEC. HFR WEB PORTAL [Internet]. 2018 [cited 2018 Jul 5]. Available from: http://hfrportal.ehealth.go.tz/

\section{Authors' Profiles}

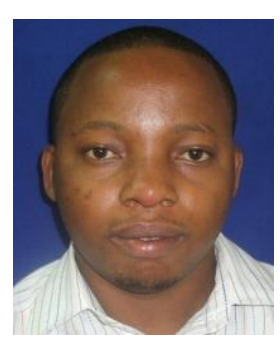

Abel Haule received his BSc in Education majoring Computer Science and Mathematics from the University of Dar es Salaam, Tanzania, in 2010. Currently, he is pursuing Master's Degree in Information and Communications Science and Engineering (ICSE) at the Nelson Mandela African Institution of Science and Technology (NM-AIST).

$\mathrm{He}$ is currently working as Lecturer and programmer at Mwenge Catholic University in Kilimanjaro, Tanzania. He has experience in system development and integration. His research interests include system development, system integration, and health systems.

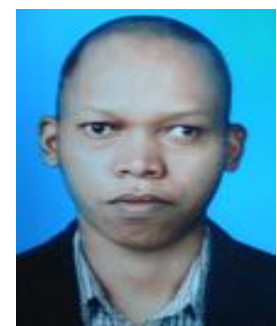

Mussa Ally Dida received his BSc in Computer Engineering and Information Technology from the University of Dar es Salaam and his MSc in Telecommunication Engineering from the University of Dodoma, both in Tanzania, in 2008 and 2011 respectively. He obtained his PhD in Information and Communication Engineering from Beijing Institute of Technology, China in 2017.

$\mathrm{He}$ is currently working as a Lecturer at the Nelson Mandela African Institute of Science and Technology (NM-AIST) in
Arusha, Tanzania. His research interests includes digital signal processing, fractional Fourier transform signals and systems, physical layer security, and multiple input multiple output (MIMO) antennas.

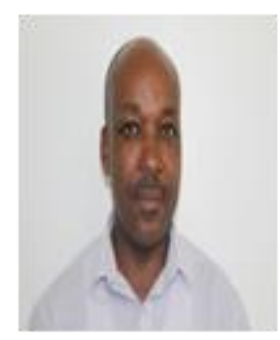

Anael Elikana Sam is a senior lecturer at the Nelson Mandela African Institution of Science and Technology (NM-AIST), Arusha, Tanzania. He is a holder of Bachelor, Master's and $\mathrm{PhD}$ in Electronics from the Slovak University of Technology in Bratislava, Slovak Republic in 1997, 1999 and 2004 respectively.

His interests are cyber security, software quality assurance, mobile and wireless communication systems, ICT for development and e-health.

How to cite this paper: Abel Haule, Mussa Ally Dida, Anael Elikana Sam, "Towards Data Exchange between Health Information System and Insurance Claims Management System", International Journal of Information Engineering and Electronic Business(IJIEEB), Vol.11, No.2, pp. 28-34, 2019. DOI: 10.5815/ijieeb.2019.02.04 